\title{
Presentation and Management of Frontoethmoid Osteoma
}

\author{
Baharudin Abdullah ${ }^{1}$ \\ ${ }^{1}$ Department of Otorhinolaryngology-Head and Neck Surgery, \\ School of Medical Sciences, Universiti Sains Malaysia, Kelantan, \\ Malaysia
}

J Neurosci Rural Pract 2019;10:551

Osteoma is the most common type of benign tumors arising from the frontal sinus. ${ }^{1}$ Tumors are slow growing and most of the times found incidentally. Frontal pain and headache are the most common presentation in patients with age group of 30 to 40 years old. Younger age group have been reported for those of Middle Eastern and West Indian in origin. ${ }^{2}$ The risk factors are not well known, but facial trauma and chronic rhinosinusitis with and without polyps have been reported. ${ }^{3}$ The other conditions that may have similar presentation and should be considered as the differential diagnosis are fibrous dysplasia and ossifying fibroma. Confirmatory diagnosis is usually made by computed tomography scan of paranasal sinuses (CT-PNS), showing a well-circumscribed hyperdense and homogenous mass in the frontoethmoid region. ${ }^{3}$ The best view to see it is on CT-PNS coronal view with bone setting.

Asymptomatic patients can be left alone, while for those who are symptomatic, the definitive treatment is open surgical removal. ${ }^{4}$ When left untreated, complication could occur as presented by Iplikcioglu and Karabag. ${ }^{5}$ Due to its location at the frontal area, which is quite restricted and due to its bony nature, it is quite challenging to perform an endoscopic approach, a preferred approach for most sinonasal tumors at present. However, a grading system based on three factors, the base of its attachment, relative size of the lesion to the frontal recess, and its location in relation to a
Address for correspondence Baharudin Abdullah, MMED (ORL-HNS), Department of Otorhinolaryngology-Head and Neck Surgery, School of Medical Sciences, Universiti Sains Malaysia, 16150 Kubang Kerian, Kelantan, Malaysia (e-mail: baharudin@usm.my).

virtual sagittal plane through the lamina papyracea, could be used to decide whether an endoscopic approach is possible. ${ }^{6}$ Nevertheless, an optimal approach is a combined open and endoscopic approach.

\section{Funding}

None.

\section{Conflict of Interest}

None declared.

\section{References}

1 Senior BA, Lanza DC. Benign lesions of the frontal sinus. Otolaryngol Clin North Am 2001;34(1):253-267

2 Atallah N, Jay MM. Osteomas of the paranasal sinuses. J Laryngol Otol 1981;95(3):291-304

3 Chahed H, Hachicha H, Bachraoui R, et al. Paranasal sinus osteomas: diagnosis and treatment. Rev Stomatol Chir Maxillofac Chir Orale 2016;117(5):306-310

4 Selleck AM, Desai D, Thorp BD, Ebert CS, Zanation AM. Management of frontal sinus tumors. Otolaryngol Clin North Am 2016;49(4):1051-1065

5 Iplikcioglu AC, Karabag $\mathrm{H}$. Frontoethmoid osteoma causing tension pneumocephalus. J Neurosci Rural Pract 2019;10(3): 548-550

6 Chiu AG, Schipor I, Cohen NA, Kennedy DW, Palmer JN. Surgical decisions in the management of frontal sinus osteomas. Am J Rhinol 2005;19(2):191-197 